\title{
Flavonol Glycosides from Saussurea controversa and Their Efficiency in Experimental Osteomyelitis
}

\section{다 (i) $(9)$}

\author{
Authors \\ Elena Avdeeva1, Elvira Shults², Marina Skorokhodova1, Yaroslav Reshetov', Ekaterina Porokhova1, Irina Sukhodolo', \\ Efim Krasnov ${ }^{1}$, Mikhail Belousov ${ }^{1}$
}

\author{
Affiliations \\ 1 Siberian State Medical University, Tomsk, Russia \\ 2 Laboratory of Medicinal Chemistry, Novosibirsk Institute \\ of Organic Chemistry, Siberian Branch, Novosibirsk, \\ Russia
}

Key words

Saussurea controversa, Asteraceae, flavonol glycosides, experimental osteomyelitis, bone marrow, bone tissue

received 27.05 .2017

revised 27.12 .2017

accepted 28.12.2017

\author{
Bibliography \\ Planta Med Int Open 2018; 5: e24-e29 \\ ISSN 2509-9264 \\ Correspondence \\ Dr. Elena Avdeeva \\ Siberian State Medical University \\ Moskovsky trakt 2 \\ Tomsk, 634050 \\ Russia \\ Tel.: + 7/98/33447381, \\ elenaavdeev@yandex.ru
}

DOI https://doi.org/10.1055/s-0044-100799

(c) Georg Thieme Verlag KG Stuttgart · New York 丹upporting information available online at

http://www.thieme-connect.de/products

\begin{abstract}
Five flavonoids were isolated from leaves of Saussurea controversa, one new flavonoid (5), three described for the first time from the genus Saussurea (1, 2, and 4), and one described previously (3). A number of flavonol glycosides can be easily isolated from the butanol fraction of the ethanol extract from $S$. controversa. As a result of separating these using column chromatography on silica gel and microcrystalline cellulose, five glycosides of quercetin were isolated in the proportional relationship of 2 (1): 8 (2): $10(3): 1$ (4): 4 (5). The structure of these substances was determined using the method of NMR by conducting various ${ }^{1} \mathrm{H}-{ }^{1} \mathrm{H}$ and ${ }^{1} \mathrm{H}-{ }^{13} \mathrm{C}$ correlation spectroscopy experiments and by comparing their spectroscopic data with published values, 5,3/,4/-trihydroxyflavone-7-O- $\alpha$-Lrhamnopyranoside-3-O- $\beta$-D-glucopyranoside (1), $5,7,3 /, 4 /$-tetrahydroxyflavone-3-O- $\beta$-D-glucopyranoside$(1 \rightarrow 6)$ - $\beta$-D-glucopyranoside- $(1 \rightarrow 6)$-O- $\alpha$-L-rhamnopyranoside (2), 5,7,3/,4/-tetrahydroxyflavone-3-O- $\beta$-D-glucopyranoside$(1 \rightarrow 6)$-O- $\alpha$-L-rhamnopyranoside (3), 5,3/,4/-trihydroxyflavone7-O- $\alpha$-L-rhamnopyranoside-3-O- $\beta$-D-xylopyranoside (4), and $5,3 /, 4 /$-trihydroxyflavone-7-O- $\beta$-D-glucopyranoside-3-O- $\alpha$-Lrhamnopyranoside-( $1 \rightarrow 2)$-O- $\beta$-D-glucopyranoside $(\mathbf{5})$. It was established for the first time that flavonol glycosides from S. controversa stimulate granulopoiesis and lymphopoiesis in the bone marrow of rats, and enhance the reparative process in the affected area in experimental osteomyelitis.
\end{abstract}

\section{Abbreviations}

TNM total number of myelokaryocytes

SCFG flavonol glycosides from Saussurea controversa

\section{Introduction}

Chronic osteomyelitis causes damage to bone tissue and bone marrow and results in significant morbidity and mortality. It was revealed in vitro that quercetin derivatives and other flavonoids effectively inhibit osteoclast proliferation and alkaline phosphatase activity and stimulate osteoblast proliferation [1,2].

Saussurea controversa DC. (Asteraceae) is a plant popularly used among the people of Siberia for the treatment of purulent wounds and diseases of the musculoskeletal system. Extracts of S. controversa exhibit anti-inflammatory and immunomodulatory activity in experimental osteomyelitis $[3,4]$. The anti-inflammatory $[5,6]$ and immunomodulatory [7] activity of the extracts may be due to phenolic compounds, particularly flavonoids, which are described in several studies. 
It is of interest to investigate flavonol glycosides from S. controversa as potential sources of its activity in cases of osteomyelitis. This study describes the isolation of five glycosides of quercetin (1-5) from S. controversa leaves, the determination of their structures, and their effect on bone marrow and bone tissue in experimental osteomyelitis.

\section{Results and Discussion}

The aqueous ethanol extract from $S$. controversa dry leaves $(0.6 \mathrm{~kg})$ was evaporated in a vacuum to remove ethanol completely, and the residue was extracted successively with chloroform, ethyl acetate, and butanol. When the butanol was removed, a yellow amorphous powder easily precipitated and was separated by decantation and dried (butanol precipitate). After separating the butanol precipitate on silica gel, we sequentially isolated quercetin-7-O- $\alpha$ L-rhamnoside-3-O- $\beta$-D-glucoside (1), quercetin-3-O- $\beta$-Ddiglucoside-O- $\alpha$-L-rhamnoside (2), and quercetin-3-rutinoside (3). The following rechromatography on microcrystalline cellulose resulted in the isolation of quercetin-7-O- $\alpha$-L-rhamnoside-3-O- $\beta$-Dxyloside (4), and quercetin-7-O- $\beta$-D-glucoside-3-O- $\alpha$-Lrhamnoside-O- $\beta$-D-glucoside (5) ( $\mathbf{F i g}$. 1). The proportional relationship of flavonoids in the butanol precipitate by weight was 2 (1): 8 (2): 10 (3): 1 (4): 4 (5).

The structures of aglycones and sugar residues in the compounds were determined by comparing their spectroscopic data with published values [8-10]. The data for ${ }^{13} \mathrm{C}$ NMR spectra of aglycones in all obtained substances were consistent with data previously described for quercetin. Proton and carbon spectra of compounds $\mathbf{1 - 3}$ and $\mathbf{5}$ contain signals characteristic for glucose and rhamnose. In compounds 3 and $\mathbf{5}$, signals in the ${ }^{13} \mathrm{C}$ NMR spectrum at 104.74, 104.67, and 102.05 (3), and at 105.09, 105.03, and 102.41 (5), as well as the number of protons in the ${ }^{1} \mathrm{H}$ NMR spectrum and data for ${ }^{1} \mathrm{H}-{ }^{1} \mathrm{H}$ COSY $2 \mathrm{D} N M R$, indicate the presence of two residues of glucose and one of rhamnose.

In compounds 1 and $\mathbf{5}$, signals in the ${ }^{13} \mathrm{C}$ NMR spectrum at $\delta$ $68.20(\mathbf{1})$ and $\delta 68.16,68.19(5)$ as well as a doublet of anomeric

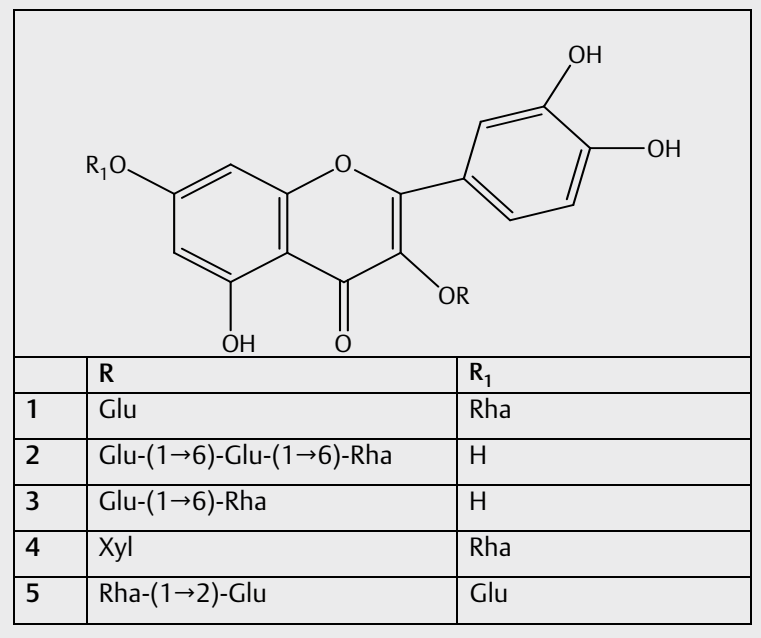

Fig. 1 The structure of flavonoids 1-5 from S. controversa. protons from glucose in the ${ }^{1} \mathrm{H}$ NMR spectrum at $\delta 5.00(\mathrm{~J}=7.5 \mathrm{~Hz}$; 1 and 5) and a singlet from rhamnose at $\delta 4.55$ (1) indicate the terminal position of these sugars. At the same time, the signal of $\mathrm{H}-1$ of a rhamnosyl moiety at $\delta 4.51$ (5) and the interaction of the signal with $\mathrm{H}-2$ of the pyranosyl moiety indicates the position between $\mathrm{C}-3$ of the aglycone and a molecule of glucose. In addition, the ${ }^{1} \mathrm{H}$ ${ }^{1} \mathrm{H}$ COSY of $\mathbf{5}$ shows the interaction of the proton of rhamnose at C-6 and protons of the phenol nucleus at C-2, 5, and 6. The key COSY ${ }^{1} \mathrm{H}-{ }^{1} \mathrm{H}$ correlations in the spectra of new compound 5 are given in > Fig. 1S, Supporting Information.

In the ${ }^{1} \mathrm{H}$ NMR spectra of both substances there is a signal at $\delta$ $12.30(\mathbf{1})$ and $\delta 12.28$ (5), characteristic of a free $5-\mathrm{OH}$ group, and there is not a signal characteristic of a free 7-OH group. In the electronic spectrum, $\mathbf{1}$ and $\mathbf{5}$ were absent a bathochromic shift with sodium acetate, but it was present when adding zirconium chloride solution and it disappeared with the subsequent addition of citric acid, which confirms the free $5-\mathrm{OH}$ position and that it was occupied by $3-\mathrm{OH}$ and $7-\mathrm{OH}$. In the ${ }^{1} \mathrm{H}-{ }^{1} \mathrm{H}$ COSY of 5 , interaction protons at $\mathrm{C}-1$ of glucose and $\mathrm{C}-2$ of rhamnose were observed, which determines the nature of the glycosidic bond between sugar residues at $3-\mathrm{OH}(\mathrm{C}-1 \rightarrow \mathrm{C}-2)$ in compound $\mathbf{5}$. In the same spectrum, the interaction of the protons of rhamnose with only one residue of glucose was observed. Thus, the position at 7-OH occupied a glucose residue.

In compounds 2 and 3, by contrast, signals in ${ }^{13} \mathrm{C}$ NMR spectra at $\delta 68.55,68.51$ (2) and $\delta 68.55$ (3) as well as doublets of anomeric protons in the ${ }^{1} \mathrm{H}$ NMR spectrum at $\delta 5.15(\mathrm{~J}=8.0 \mathrm{~Hz})$ and $\delta 5.14$ ( 2 and 3, respectively) indicate the position of the glucose between $\mathrm{C}-3$ of the aglycone and a molecule of rhamnose, while a singlet of rhamnose of $\mathrm{H}-1$ at $\delta 4.55$ ( 2 and 3 ) indicates the terminal position of this sugar. Signals in the ${ }^{1} \mathrm{H}$ NMR spectra for $5-\mathrm{OH} \delta 12.35$ ( 2 and 3) and 7-OH $\delta 7.87(2), \delta 7.95(3)$ indicate the free position of these groups. Data for the ${ }^{1} \mathrm{H}-{ }^{1} \mathrm{H}$ COSY, ${ }^{1} \mathrm{H}-{ }^{13} \mathrm{CCOHX}$, and COLOC 2D NMR spectra of compounds $\mathbf{2}$ and $\mathbf{3}$ enabled the nature of the glycosidic bond between molecules of glucose and rhamnose at 3-OH to be established: $C-6 \rightarrow C-1$ ( 2 and 3 ). The $\beta$-configuration of glucose residues and the $\alpha$-configuration of rhamnose were proven based on the respective magnitudes of their constant ].

From this data, the structure of compound $\mathbf{1}$ was identified as 5,3/,4/-trihydroxyflavone-7-O- $\alpha$-L-rhamnopyranoside-3-O- $\beta$-Dglucopyranoside [11], 2 as 5,7,3/,4/-tetrahydroxyflavone-3-O- $\beta$-Dglucopyranoside- $(1 \rightarrow 6)$ - $\beta$-D-glucopyranoside- $(1 \rightarrow 6)-O-\alpha-L-$ rhamnopyranoside [12], 3 as 5,7,3/,4/-tetrahydroxyflavone-3-O- $\beta$ D-glucopyranoside-( $1 \rightarrow 6)-O-\alpha$-L-rhamnopyranoside [9], and 5 as 5,3/,4/-trihydroxyflavone-7-O- $\beta$-D-glucopyranoside-3-O- $\alpha$-Lrhamnopyranoside-( $1 \rightarrow 2)-0-\beta$-D-glucoyranoside. The flavonoid structure $\mathbf{5}$ is similar to quercetin 3-O-rutinoside-7-O-glucoside [13], but the position of the sugar at C-3 is different. We did not find data on flavonoid $\mathbf{5}$ in the literature.

The sugar components of $\mathbf{4}$ (xylose and rhamnose) were determined after acid hydrolysis by identification with reliable samples in the butanol-pyridine-water system (6:4:3, detector: anilin phthalate solution). Electronic spectra with ionizing reagents showed the absence of an expressed bathochromic shift with a sodium acetate and zirconium chloride solution in the presence of citric acid, which indicates the bonding of sugar residues at positions 3 and 7 of the flavone ring. This was confirmed by the absence of a signal that is 
- Table 1 Bone marrow cells of rats with experimental osteomyelitis before (group 2) and after the introduction of Cefazolin (group 3) and SCFG (group 4).

\begin{tabular}{|c|c|c|c|c|}
\hline \multirow[t]{2}{*}{ Indicator } & \multicolumn{4}{|c|}{ The number of cells $\times 10^{6}$ on the femur $(M \pm m, n=6)$} \\
\hline & Group 1 & Group 2 & Group 3 & Group 4 \\
\hline Erythroblasts & $0.64 \pm 0.15$ & $0.45 \pm 0.11$ & $0.21 \pm 0.03^{1}$ & $0.37 \pm 0.07$ \\
\hline Pronormoblasts & $3.66 \pm 0.62$ & $1.33 \pm 0.06^{1}$ & $0.61 \pm 0.03^{1}$ & $1.46 \pm 0.33^{1,3}$ \\
\hline Basophilic normoblasts & $4.68 \pm 0.23$ & $3.08 \pm 0.16$ & $1.56 \pm 0.18^{1}$ & $3.93 \pm 0.51^{3}$ \\
\hline Polychromatophilic normoblasts & $13.91 \pm 1.26$ & $9.52 \pm 0.94^{1}$ & $7.72 \pm 0.34^{1}$ & $9.66 \pm 0.77^{1}$ \\
\hline Oxyphilic normoblasts & $11.20 \pm 1.48$ & $9.10 \pm 0.59$ & $5.60 \pm 0.371$ & $8.32 \pm 0.90$ \\
\hline The mitoses of erythrocytes & $1.92 \pm 0.09$ & $1.37 \pm 0.08$ & $0.80 \pm 0.071$ & $1.44 \pm 0.14$ \\
\hline The total number of erythrokaryocytes & $36.01 \pm 3.84$ & $24.85 \pm 1.95^{1}$ & $16.50 \pm 1.00^{1}$ & $25.19 \pm 2.76^{1,3}$ \\
\hline Myeloblasts & $1.65 \pm 0.22$ & $0.58 \pm 0.04^{1}$ & $0.19 \pm 0.03^{1}$ & $0.70 \pm 0.11$ \\
\hline Promyelocytes & $3.88 \pm 0.50$ & $0.98 \pm 0.28^{1}$ & $2.04 \pm 0.26^{2}$ & $1.75 \pm 0.30^{2}$ \\
\hline Myelocytes & $3.66 \pm 0.85$ & $1.62 \pm 0.41^{1}$ & $1.46 \pm 0.171$ & $1.90 \pm 0.651$ \\
\hline Metamyelocytes & $4.66 \pm 0.67$ & $3.00 \pm 0.34^{1}$ & $1.66 \pm 0.24^{1}$ & $4.83 \pm 0.25^{2,3}$ \\
\hline Rod-nuclear neutrophils & $14.18 \pm 1.37$ & $6.50 \pm 0.95^{1}$ & $4.05 \pm 0.38^{1}$ & $12.88 \pm 1.10^{2,3}$ \\
\hline Segmentonuclear neutrophils & $10.98 \pm 1.29$ & $12.10 \pm 1.14$ & $5.49 \pm 0.64^{1}$ & $12.29 \pm 1.61$ \\
\hline Eosinophils & $5.04 \pm 0.60$ & $5.07 \pm 0.40$ & $3.15 \pm 0.30^{1}$ & $4.79 \pm 0.33$ \\
\hline Basophils & $0.46 \pm 0.01$ & $0.28 \pm 0.01$ & $0.20 \pm 0.01$ & $0.36 \pm 0.01$ \\
\hline The mitosis of myelocytes & $1.51 \pm 0.18$ & $0.64 \pm 0.05$ & $0.26 \pm 0.03^{1}$ & $0.62 \pm 0.13$ \\
\hline The total number of granulocytes & $49.55 \pm 5.41$ & $30.77 \pm 3.62^{1}$ & $18.20 \pm 2.08^{1}$ & $40.15 \pm 4.90^{2,3}$ \\
\hline Monocytes & $4.26 \pm 0.52$ & $5.46 \pm 0.73$ & $2.84 \pm 0.33^{2}$ & $2.85 \pm 0.49^{2}$ \\
\hline Megakaryocytes & $0.46 \pm 0.01$ & $1.96 \pm 0.33^{1}$ & $0.27 \pm 0.01^{2}$ & $0.95 \pm 0.32^{2}$ \\
\hline Lymphocytes & $16.70 \pm 1.81$ & $6.94 \pm 1.00^{1}$ & $4.07 \pm 0.35^{1}$ & $16.34 \pm 1.83^{2,3}$ \\
\hline The plasma cells & $1.02 \pm 0.43$ & $1.96 \pm 0.40$ & $0.56 \pm 0.11^{2}$ & $1.83 \pm 0.33$ \\
\hline Maturation index of neutrophils & $0.48 \pm 0.01$ & $0.30 \pm 0.01$ & $0.43 \pm 0.05$ & $0.34 \pm 0.01$ \\
\hline Maturation index of erythrokaryocytes & $0.70 \pm 0.01$ & $0.75 \pm 0.01$ & $0.80 \pm 0.05$ & $0.70 \pm 0.01$ \\
\hline Leucoerythroblastic ratio & $1.96 \pm 0.05$ & $1.73 \pm 0.05$ & $1.46 \pm 0.05^{1}$ & $2.45 \pm 0.05^{2}$ \\
\hline TNM & $91.50 \pm 1.75$ & $56.00 \pm 2.90^{1}$ & $38.12 \pm 2.60^{12}$ & $73.20 \pm 2.65^{2,3}$ \\
\hline
\end{tabular}

characteristic for a free $7-\mathrm{OH}$ group in the ${ }^{1} \mathrm{H}$ NMR spectrum. The signals for five carbon atoms from one of the sugars in the ${ }^{13} \mathrm{C} \mathrm{NMR}$ spectrum are consistent with those for xylose $[14,15]$. The presence of a singlet at $\delta 4.53$ in the ${ }^{1} \mathrm{H}$ NMR spectrum and the signal at $\delta 17.61$ in the ${ }^{13} \mathrm{C}$ NMR spectrum confirm that the second sugar is rhamnose. From this data, the structure of compound 4 was identified as 5,3/,4/-trihydroxyflavone-7-O- $\alpha$-L-rhamnopyranoside-3O- $\beta$-D-xylopyranoside (PubChem CID:44259241). Flavonoids 1, 2, $\mathbf{4}$, and $\mathbf{5}$ were described for the first time for the genus Saussurea. Flavonoid $\mathbf{5}$ was described for the first time ever.

The effect of flavonoids from S. controversa on bone marrow and bone tissue was researched in experimental osteomyelitis. The development of experimental osteomyelitis led to a decrease in the TNM in the bone marrow of rats by $38 \%$ compared to the intact group ( $\triangleright$ Table 1 ). The decrease in the TNM was driven primarily by a $58 \%$ decrease in the number of lymphocytes and by an average decrease of $34 \%$ in the number of young and mature cell forms of the granulocytes and erythrocytes. As a result of experimental osteomyelitis in rats, the number of megakaryocytes increased by a factor of four; furthermore, a large number of destroyed lymphocytes was observed. Greater inhibition of myelopoiesis was observed after antibiotic treatment in the bone marrow of rats with experimental osteomyelitis.
After the course of using the SCFG in the proportional relationship of $2(\mathbf{1}): 8(2): 10(3): 1(4): 4(5)$, in a dose of $10 \mathrm{mg} / \mathrm{kg}$, the number of bone marrow granulocytes and lymphocytes increased significantly, indicating stimulation of myelopoiesis under these conditions. Using the SCFG led to an average decrease of $51 \%$ in the number of megakaryocytes.

During a morphological study in the femoral diaphysis of rats on the $36^{\text {th }}$ day after the modeling of osteomyelitis (group 2), signs of pronounced inflammation were noted. Leukocytic infiltration and hyperemia of blood vessels were observed in bone marrow spaces. Necrosis and autolysis of bone plates in the cortical and trabecular layers with the formation of sequesters were discovered. The normal structure of osteons was disrupted ( $\triangleright$ Fig. 2).

In the group of rats treated with Cefazolin (group 3), diffuse inflammation was observed, but its intensity was lower. Discomplexation of bone plates remained. The process of bone resorption prevailed over the process of osteogenesis.

In the group of rats treated with SCFG (group 4), a decrease in the intensity of inflammatory processes was noted. Signs of regenerative processes (activation of endoosteum and periosteum, the formation of granulation tissue) were visible throughout the femur, but more pronounced in the epiphysis. Most of the bone plates had a normal structure and uniform mineralization. 


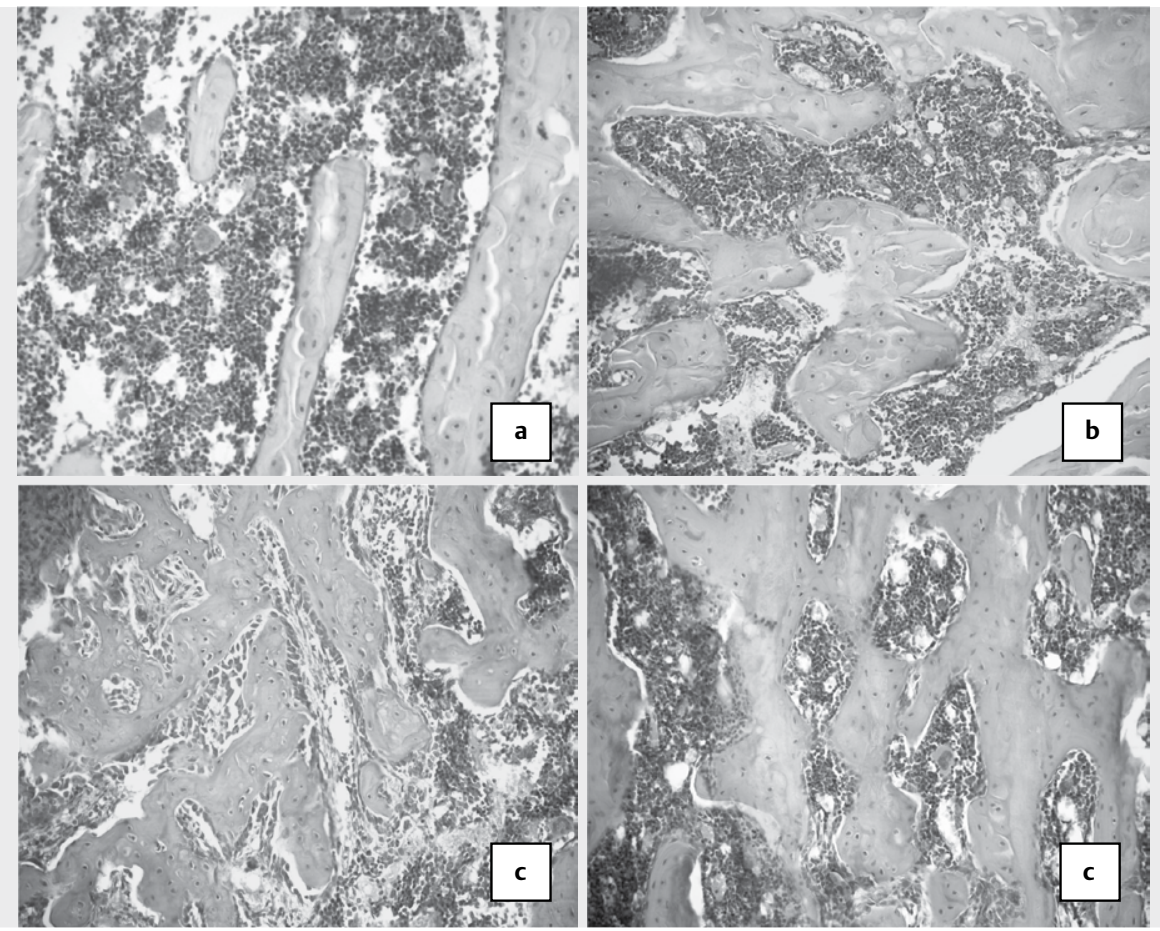

- Fig. 2 The section of the femoral diaphysis of rats on the $36^{\text {th }}$ day after modeling of osteomyelitis without treatment showed signs of inflammation without apparent activation of osteogenesis a; after treatment with antibiotic, signs of inflammation remained and there was a slight activation of osteogenesis b; after the SCFG treatment, activation of osteoblastic processes was observed at the location of dead osteons c. Staining was done with hematoxylin and eosin, $\times 200$.

Thus, flavonoids are a potential remedy for integrated treatment of osteomyelitis by stimulating myelopoiesis and the regeneration of bone tissue.

Despite the wide potential for the application of species of Saussurea in medicine, the chemical composition and biological activity of many of them are poorly understood. The people of Siberia successfully apply $S$. controversa as anti-inflammatory and immunomodulatory agents, as well as in bone pathology, but the structure of the active molecules, including flavonoids, which have a number of biological effects, still has not been established. A complex of five quercetin glycosides isolated from S. controversa improves the condition of bone marrow and enhances reparative processes in bone tissue during standard antibiotic treatment of osteomyelitis. The nature of aglycones and sugar residues of flavonoids was established using NMR ${ }^{1} \mathrm{H}-{ }^{1} \mathrm{H}$, and ${ }^{1} \mathrm{H}-{ }^{13} \mathrm{C}$ with careful comparison of the data. COSY, COLOC, and ROESY experiments allowed for establishing the point of attachment of sugar residues and the nature of the glycosidic linkages. Compounds 1, 2, 4, and 5 had not been described previously for the genus Saussurea. Flavonoid $\mathbf{5}$ had not been described previously in the literature.

\section{Materials and Methods}

\section{General experimental procedures}

The NMR spectra for the solutions of the compounds in $\mathrm{CD}_{3} \mathrm{OD}$ were recorded on the Bruker AV-600 spectrometer [600.30 $\left({ }^{1} \mathrm{H}\right)$, $\left.150.95 \mathrm{MHz}\left({ }^{13} \mathrm{C}\right)\right]$. Chemical shifts were reported in ppm $(\delta)$ relative to internal TMS for all the signs that could be identified with certainty. Coupling constants (J) were measured in $\mathrm{Hz}$. The NMR signals were determined by using various ${ }^{1} \mathrm{H}-{ }^{1} \mathrm{H}$ and ${ }^{1} \mathrm{H}-{ }^{13} \mathrm{C}$ correlation spectroscopy experiments (COSY, HMBC, COLOC, COXH, and ROESY). The specific rotation values $[\alpha]^{25}$ were determined on a PolAAr 3005 polarimeter, and expressed in $(\mathrm{deg} \times \mathrm{mL}) /(\mathrm{g} \times \mathrm{dm})$, while concentration was expressed in g per $100 \mathrm{~mL}$ of solution. The melting points were determined on a Stuart SMF-38 melting point apparatus and are uncorrected. UV spectra were obtained on an HP 8453 UV-Vis spectrometer (Hewlett-Packard) in EtOH solutions $\left(10^{-4} \mathrm{~mol} / \mathrm{L}\right)$. CHN analysis was carried out on a Carlo Erba $1106 \mathrm{el}-$ emental analyzer.

\section{Plant material}

Leaves of S. controversa were collected in the region of Irkutsk, Russia, during the flowering phase in July of 2013 and were air-dried. The plants were collected by Prof. A. A. Semenov and identified by Prof. M. N. Shurupova. A voucher specimen (No.TK-004605) has been deposited at the Herbarium of Tomsk State University (Tomsk, Russia).

\section{Extraction and isolation}

Raw materials $(600 \mathrm{~g})$ were extracted with hot $40 \% \mathrm{EtOH}$ $\left(3 \times 6000 \mathrm{~mL}, 80^{\circ} \mathrm{C}, 1 \mathrm{~h}\right.$ each). The extract was filtered and evaporated until it became an aqueous residue, which was treated sequentially in a separating funnel with $\mathrm{CHCl}_{3}(3 \times 200 \mathrm{~mL})$, ethyl acetate $(6 \times 200 \mathrm{~mL})$, and $\mathrm{n}$-butanol $(10 \times 200 \mathrm{~mL})$. After removal of the solvents, a $0.72-\mathrm{g}\left(0.12 \%\right.$ on air-dried raw material) $\mathrm{CHCl}_{3}$ fraction and a $4.38 \mathrm{~g}$ g $(0.73 \%)$ ethyl acetate fraction were obtained. When butanol was removed, yellow amorphous powder easily pre- 
cipitated and was separated by decantation and dried; its weight was $2.0 \mathrm{~g}$. After the residue was dried, a butanol faction with a yield of $11.00 \mathrm{~g}(1.83 \%)$ was obtained.

Through chromatography of the butanol precipitate $(1.5 \mathrm{~g})$ on silica gel $(2.5 \times 70 \mathrm{~cm}$; Lachema L 100/250) using ethyl acetate with a gradual increase in the content of $\mathrm{EtOH}$ (5-80\%), three flavonoids were successively isolated: $\mathbf{1}$ (yield $0.080 \mathrm{~g}$ ), $\mathbf{2}$ (yield $0.468 \mathrm{~g}$ ), and 3 (yield $0.570 \mathrm{~g}$ ). In the following rechromatography, fractions of the butanol precipitate on microcrystalline cellulose $(2.3 \times 60 \mathrm{~cm}$; Lachema $)$ using water with a gradual increase in the content of $\mathrm{EtOH}$ (5-90\%), two other flavonoids were successively obtained: 4 (yield $0.067 \mathrm{~g}$ ) and $\mathbf{5}$ (yield $0.216 \mathrm{~g}$ ).

\section{Biological experiments}

Biological experiments were carried out on 24 male Wistar rats, aged 3 months and weighing 300-350 g (Laboratory of Biological Modeling at Siberian State Medical University, Tomsk). Animals were kept in standard conditions with free access to water and food. The experimental studies were governed by the principles set out in the European Community directives (86/609/EEC) and the Helsinki Declaration, and were approved by the local ethical committee of Siberian State Medical University (No. 4316 from 9 November 2015).

The rats were divided into four groups: intact (group 1), experimental osteomyelitis (group 2), experimental osteomyelitis treated with Cefazolin (group 3), and experimental osteomyelitis treated with SCFG (group 4). Experimental osteomyelitis of the right femur was simulated in the rats of groups 2-4 [16]. The complex of SCFG in the proportional relationship of 2 (1): 8 (2): 10 (3): 1 (4): 4 (5) was administered intragastrically in a water suspension at a dose of $10 \mathrm{mg} / \mathrm{kg}$ in a volume of $2 \mathrm{~mL}$ for 28 days. The antibiotic Cefazolin (purity 99\%; Rusfarm), which is used as the standard treatment of osteomyelitis, was administered intramuscularly in a dose of $50 \mathrm{mg} / \mathrm{kg}$ for 5 days.

After euthanasia by $\mathrm{CO}_{2}$ asphyxia on day 36 of the experiment, the condition of bone marrow hematopoiesis in the rats was examined by counting the TNM on the femur (10\%/femur) and myelogram on smears prepared from the homogenate of fragment myeloid tissue taken from a segment of the sternum and autologous serum (1:1), stained using Nocht's azure II-eosin. The percentage of separate cell forms when counting myelograms of the rats was translated into absolute numbers of cells on the femur $\times 10^{6}$.

For the histological examination, the right femur was decalcified using Grip's method [17], dehydrated in EtOH, and embedded in paraffin. Sections $7 \mu \mathrm{m}$ thick were deparaffinized and stained with hematoxylin and eosin.

\section{Statistical analysis}

Statistical processing of the results was carried out using the Statistica 8.0 statistical analysis software package. To evaluate the significance of differences between samples, we used nonparametric Mann-Whitney criteria with a calculation of the arithmetic mean M and its standard error. Statistically significant differences were considered at $\mathrm{p}<0.05$.
Quercetin 7-O- $\alpha$-L-rhamnoside-3-O- $\beta$-D-glucoside (1): light yellow, amorphous powder ( $\left.\mathrm{MeOH}-\mathrm{CHCl}_{3}\right)$; m.p. $188-190{ }^{\circ} \mathrm{C}$; $[\alpha]^{25}{ }_{D}+48$ (c 0.28, EtOH); UV (MeOH) $\lambda_{\max } 290,355 \mathrm{~nm}$ [11].

Quercetin 3-O- $\beta$-D-diglucoside-O- $\alpha$-L-rhamnoside (2): light yellow, amorphous powder $\left(\mathrm{MeOH}-\mathrm{CHCl}_{3}\right)$; m.p. $175-176{ }^{\circ} \mathrm{C}$; $[\alpha]^{25} \mathrm{D}+66$ (c 0.42, EtOH); UV (MeOH) $\lambda_{\max } 292,357 \mathrm{~nm}$; anal C 50.66, $\mathrm{H}$ 5.05, O 44.29, calcd. for $\mathrm{C}_{33} \mathrm{H}_{40} \mathrm{O}_{18}, 724$ [12].

Quercetin 7-O- $\alpha$-L-rhamnoside-3-O- $\beta$-D-xyloside (4): yellow, amorphous powder $\left(\mathrm{MeOH}-\mathrm{CHCl}_{3}\right)$; m.p. $183-185^{\circ} \mathrm{C} ;[\alpha]^{25}{ }_{\mathrm{D}}+78$ (c 0.26, EtOH); UV (MeOH) $\lambda_{\max } 294,334 \mathrm{~nm} ;{ }^{1} \mathrm{H}$ NMR $\left(\mathrm{CD}_{3} \mathrm{OD}\right.$, $600 \mathrm{MHz}$ ) $\delta 5.14$ (d, 8.0, C-1//I), 3,46 (d, 8.0, C-2//I), 3.50 (d, 8.0, C-3//l), 3.57 (m, C-4//l), 3.42, $3.82(\mathrm{~d}, 10.0, \mathrm{C}-5 / / /)$; $4.53(1 \mathrm{H}, \mathrm{s})$, 3.26-3.40 (4H, m), $1.18(3 \mathrm{H}, \mathrm{d}, 6.0)$; $8.06(3 /-\mathrm{OH}), 8.11(4 /-\mathrm{OH})$, $12.26(5-\mathrm{OH}) ;{ }^{13} \mathrm{C} \mathrm{NMR}\left(\mathrm{CD}_{3} \mathrm{OD}, 150 \mathrm{MHz}\right) \mathrm{d} 105.33$ (C-1//I), 74.90 (C-2//I), 77.62 (C-3//I), 68.93 (C-4//I), 67.91 (C-5//I); $101.76(\mathrm{C}-1 / /)$, 71.66 (C-2//), 70.33 (C-3//), 71.28 (C-4//), 73.45 (C-5//), 17.61 (C-6//).

Quercetin 7-O- $\beta$-D-glucoside-3-O- $\alpha$-L-rhamnoside-O- $\beta$-Dglucoside (5): yellow, amorphous powder ( $\left.\mathrm{MeOH}-\mathrm{CHCl}_{3}\right)$; m.p. 197-199 ${ }^{\circ} \mathrm{C} ;[\alpha]^{25} \mathrm{D}+72$ (c 0.36, EtOH); UV (MeOH) $\lambda_{\max } 293$, $326 \mathrm{~nm} ;{ }^{1} \mathrm{H}$ NMR $\left(\mathrm{CD}_{3} \mathrm{OD}, 600 \mathrm{MHz}\right) \delta 5.00(1 \mathrm{H}, \mathrm{d}, 7.5), 3.40-3.68$ $(8 \mathrm{H}, \mathrm{m}), 3.60(2 \mathrm{H}, \mathrm{dd}, 9.0,2.0), 3.81(2 \mathrm{H}, \mathrm{d}, 10.0) ; 4.51(1 \mathrm{H}, \mathrm{s})$, 3.39-3.66 (4H, m), $1.17(3 \mathrm{H}, \mathrm{d}, 6.0) ; 8.08(3 /-\mathrm{OH}), 8.10(4 /-\mathrm{OH})$, $12.28(5-\mathrm{OH}) ;{ }^{13} \mathrm{CNMR}\left(\mathrm{CD}_{3} \mathrm{OD}, 150 \mathrm{MHz}\right) \mathrm{d} 105.03$ (C-1//I), 105.09 (C-1/III), 75.23, 76.67, 71.63, 77.82, 68.16 (C-6//I), 68.19 (C-6/III); $102.02(\mathrm{C}-1 / /), 71.88\left(\mathrm{C}-2^{/ /}\right), 70.77(\mathrm{C}-3 / /), 69.26(\mathrm{C}-4 / /), 73.63$ (C$5 / /), 17.74(\mathrm{C}-6 / /)$.

\section{Supporting information}

Microscopic sections of the affected area of the femurs of rats before and after treatment, tables with the NMR data for compounds 1-5, spectra for ${ }^{1} \mathrm{H}$ NMR, ${ }^{13} \mathrm{C}$ NMR, COLOC, and COXH for compound $\mathbf{5}$, and key COSY correlations for compound $\mathbf{5}$ are available as Supporting Information.

\section{Acknowledgments}

The authors would like to acknowledge the Multi-Access Chemical Service Center SB RAS for spectral and analytical measurements (Novosibirsk).

\section{Conflict of Interest}

The authors declare no conflict of interest.

References

[1] Shou D, Zhang Y, Shen L, Zheng R, Huang X, Mao Z, Yu Z, Wang N, Zhu Y. Flavonoids of Herba Epimedii enhances bone repair in a rabbit model of chronic osteomyelitis during post-infection treatment and stimulates osteoblast proliferation in vitro. Phytother Res 2017; 31: 330-339

[2] Kim CS, Ha HK, Song KY. Therapeutic agent or osteoporosis comprising an active ingredient of quercetin derivatives. US Patent 01622472004 ; 
[3] Avdeeva EY, Saprykina EV, Slizovsky GV, Krasnov EA, Pechenko VG. Study of biochemical activities of extracts of Saussurea controversa DC and Filipendula ulmaria (L.) Maxim. in experimental osteomyelitis. Bull Siberian Med 2016; 2: 5-12

[4] Perevozchikova TV, Avdeeva EY, Fayt EA, Skorokhodova MG, Krasnov EA. The effect of extracts of Saussurea controversa and Fillipendula ulmaria on immunological reactivity of rats with experimental osteomyelitis. Exp Clin Pharmacol 2016; 7: 16-20; Internet: http://www.ekf.folium.ru/index.php/ekf/article/view/1800

[5] Granica S, Czerwińska ME, Żyżyńska-Granica B, Kiss AK. Antioxidant and anti-inflammatory flavonol glucuronides from Polygonum aviculare L. Fitoterapia 2013; 9: 180-188

[6] Czerwińska ME, Świerczewska A, Woźniak M, Kiss AK. Bioassay-guided isolation of iridoids and phenylpropanoids from aerial parts of Lamium album and their anti-inflammatory activity in human neutrophils. Planta Med 2017; 83: 1011-1019

[7] Ielpo MT, Basile A, Miranda R, Moscatiello V, Nappo C, Sorbo S, Laghi E, Ricciardi MM, Ricciardi L, Vuotto ML. Immunopharmacological properties of flavonoids. Fitoterapia 2000; 1: S101-S109

[8] Hasler A, Gross GA, Meier B, Sticher O. Complex flavonol glycosides from the leaves of Ginkgo biloba. Phytochemistry 1992; 4: 1391-1394

[9] Srinivasan R, Natarajan D, Shivakumar MS. Antioxidant compound Quercetin-3-O- $\lambda$-L-rhamnoside( $1 \rightarrow 6)-\beta$-D-glucose (Rutin) isolated from ethyl acetate leaf extracts of Memecylon edule Roxb (Melastamataceae). Free Rad Antiox 2015; 1: 35-42
[10] Weckerle B, Michel K, Balázs B, Schreier P, Tóth G. Quercetin 3,3', 4'-tri-O- $\beta$-D-glucopyranosides from leaves of Eruca sativa (Mill.). Phytochemistry 2001; 57: 547-551

[11] Aboushoer MI, Fathy HM, Abdel-Kader MS, Goetz G, Omar AA. Terpenes and flavonoids from an Egyptian collection of Cleome droserifolia. Nat Prod Res 2010; 7: 687-696

[12] Sharaf M, el-Ansari MA, Saleh NA. Quercetin triglycoside from Capparis spinosa. Phytochemistry 2000; 71: 46-49

[13] Al-Taweel AM, Abdel-Kader MS, Fawzy GA, Perveen S, Maher HM, Al-Zoman NZ, Al-Shehri MM, Al-Johar H, Al-Showiman H. Isolation of flavonoids from Delonix elata and determination of its rutin content using capillary electrophoresis. Pak J Pharm Sci 2015; 5: 1897-1903

[14] Jain N, Sarwar Alam M, Kamil M, llyas M, Niwa M, Sakae A. Two flavonol glycosides from Chenopodium ambrosioides. Phytochemistry 1990; 12: 3988-3991

[15] Nielsen AH, Olsen CE, Møller BL. Flavonoids in flowers of 16 Kalanchoë blossfeldiana varieties. Phytochemistry 2005; 66: 2829-2835

[16] Avdeeva EY, Slizovsky GV, Skorokhodova MG, Fomina TI, Zorkaltsev MA, Zavadovskaya VD. The modeling experimental traumatic osteomyelitis in rats. Bull Exp Biol Med 2016; 1: 157-160; Internet: http://www.iramn.ru/journal/bebm/2016/bbm1601.htm

[17] Everson Pearse AG. Histochemistry, theoretical and applied. 2nd editionLondon: Churchill; 1960: 777-778 